\title{
Detection of Welding Defects using S-TOFD and Digital Image Processing Techniques
}

\author{
Ramamoorthi P V \\ SASTRA University, \\ Thanjavur, India
}

\author{
Srinivasan $\mathrm{R}$ \\ SASTRA University, \\ Thanjavur, India
}

\author{
Vijayarekha K \\ SASTRA University, \\ Thanjavur, India
}

\author{
Venkataraman B \\ Indira Gandhi Centre for \\ Atomic Research, \\ Kalpakkam, India
}

\begin{abstract}
Ultrasonic Techniques are most widely used for defect detection in welding. A major issue in this process is the actual identification of the defect. Especially in case of TOFD welding defects, the resultant aberrations on the scan are often confused with granulation due to noise. In this paper, we have used an innovative image processing technique which segments the manually selected portion of the image and further processes it and also gives the dimensions and location of the flaw, if any. A comparative study of the various results of further processing has been made, and an appropriate choice of the technique best suited for the image can be made, depending upon the imaging modality, noise levels, etc. Scan images from actual readings taken by Shear-wave Time of Flight Diffraction (s-TOFD) technique have also been presented with their respective processed results.
\end{abstract}

\section{General Terms}

Time of Flight Diffraction (TOFD), Non-Destructive Evaluation (NDE), Weld Defects, Segmentation

\section{Keywords}

Image Processing, Image Segmentation, Welding.

\section{INTRODUCTION}

\subsection{Introduction to Ultrasonic TOFD \\ Technique}

Before ultrasound techniques came into existence, X-Ray imaging ${ }^{[1]}$ was most commonly used for flaw detection. The main disadvantage of this method was that it was not possible to use the apparatus in places where space was constrained. Another major drawback was that the detection of nearsurface flaws was almost impossible. Ultrasound techniques overcome these limitations with their easy portability and accurate detection of flaws, even closer than $0.3 \mathrm{~mm}$ to the surface. The results of these techniques can be obtained in various forms as required for the task at hand, unlike the $\mathrm{X}$ ray, which gives only one type of output irrespective of the necessity. Since we are focusing on the Non-Destructive Testing (NDT) technique of the given sample, the most common modes of presenting the scans are the A-scan (displays the amount of received ultrasonic energy as a function of time), B-scan (profile or cross-sectional view of the test specimen) and C-scan (plan-type view of the location and size of test specimen features). In this paper, we have used the B-scan images of welded joints to detect the flaws present.
The common welding defects include Lack of fusion, Cracking, Lack/Excess penetration, porosity inclusions and undercut to name a few. These abnormalities can prove devastating in many cases like nuclear power-plants, etc. The NDT techniques can be used for easy detection of these flaws. Earlier, conventional Ultrasound Technique (UT) was used. Later, it was found that TOFD fared over UT on many counts ${ }^{[2]}$ such as independence from the orientation and size of flaw, high Probability of Detection (POD), cost-effectiveness, etc. TOFD has also been found to fare over the other common UT methods like Phased-array UT, Pulse echo Ultrasound and Doppler-wave technique. Another reason why TOFD is preferred for this specific process is that it can be operated at temperatures over $200^{\circ} \mathrm{C}-$ a temperature most common during welding.

\subsection{Comparison of the Ultrasound TOFD Technique with other NDT}

Table 1: A Characteristic comparison of the NDT Techniques ${ }^{[3]}$

\begin{tabular}{|c|c|c|c|c|}
\hline Factor & TOFD & $\begin{array}{c}\text { X-Ray } \\
\text { (RT) }\end{array}$ & $\begin{array}{c}\text { Eddy } \\
\text { Current }\end{array}$ & $\begin{array}{c}\text { Magnetic } \\
\text { Particle }\end{array}$ \\
\hline 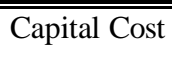 & $\begin{array}{l}\text { Medium } \\
\text { to High }\end{array}$ & $\overline{~ H i g h}$ & $\begin{array}{l}\text { Low to } \\
\text { Medium }\end{array}$ & "Medium \\
\hline $\begin{array}{c}\text { Working } \\
\text { Cost }\end{array}$ & Very low & High & Low & Medium \\
\hline $\begin{array}{l}\text { Time to } \\
\text { obtain } \\
\text { Results }\end{array}$ & Immediate & Delayed & Immediate & $\begin{array}{l}\text { Short } \\
\text { Delay }\end{array}$ \\
\hline $\begin{array}{l}\text { Type of } \\
\text { Defect }\end{array}$ & Internal & Most & External & External \\
\hline $\begin{array}{l}\text { Relative } \\
\text { Sensitivity }\end{array}$ & High & Medium & High & Low \\
\hline $\begin{array}{l}\text { Operator } \\
\text { Skill }\end{array}$ & High & High & Medium & Low \\
\hline $\begin{array}{l}\text { Portability } \\
\text { of } \\
\text { Equipment }\end{array}$ & High & Low & $\begin{array}{l}\text { High to } \\
\text { Medium }\end{array}$ & $\begin{array}{l}\text { High to } \\
\text { Medium }\end{array}$ \\
\hline $\begin{array}{l}\text { Dependency } \\
\text { on Material } \\
\text { Composition }\end{array}$ & Very & Quite & Very & $\begin{array}{c}\text { Magnetic } \\
\text { Only }\end{array}$ \\
\hline
\end{tabular}


Table 2: A Comparison of the Advantages and Disadvantages of Various NDT Methods ${ }^{[3][4]}$

\begin{tabular}{|c|c|c|}
\hline Technique & Advantage & Disadvantage \\
\hline TOFD & $\begin{array}{l}\text { Superior Depth of } \\
\text { Penetration, Only } \\
\text { single sided access } \\
\text { required, provides } \\
\text { distance information, } \\
\text { easy automation }\end{array}$ & $\begin{array}{l}\text { Needs a fluid couplant, } \\
\text { smooth surface and } \\
\text { reference standards }\end{array}$ \\
\hline X-Ray (RT) & $\begin{array}{l}\text { Can be used to inspect } \\
\text { almost all materials, } \\
\text { defects both surface } \\
\text { and sub-surface defects }\end{array}$ & $\begin{array}{l}\text { Requires high skill, } \\
\text { access to both sides of } \\
\text { structure and critical } \\
\text { orientation of radiation } \\
\text { beam. Relatively } \\
\text { expensive equipment and } \\
\text { radiation hazard from } \\
\text { extensive exposure }\end{array}$ \\
\hline $\begin{array}{l}\text { Eddy } \\
\text { Current }\end{array}$ & $\begin{array}{c}\text { Detects surface and } \\
\text { near-surface defects, } \\
\text { Readily automated, } \\
\text { moderate costs }\end{array}$ & $\begin{array}{l}\text { Limited to inspection of } \\
\text { conductive materials, } \\
\text { Limited depth of } \\
\text { penetration, Requires } \\
\text { high skill and reference } \\
\text { standards }\end{array}$ \\
\hline $\begin{array}{l}\text { Magnetic } \\
\text { Particle }\end{array}$ & $\begin{array}{l}\text { Rapid inspection of } \\
\text { large surface areas, } \\
\text { detecting both - surface } \\
\text { and sub-surface flaws, } \\
\text { relatively low } \\
\text { equipment cost }\end{array}$ & $\begin{array}{l}\text { Limited to ferromagnetic } \\
\text { materials, limited } \\
\text { penetration depth, } \\
\text { requires demagnetization } \\
\text { and post-cleaning and } \\
\text { critical alignment of } \\
\text { Magnetic Field }\end{array}$ \\
\hline
\end{tabular}

\section{IMAGE ACQUISITION AND PRE- PROCESSING}

TOFD experiment model Microplux of M9S AEA technology, U.K with manual scanner along with longitudinal wave ( $4 \mathrm{MHz}$ ) angle beam probe of $45^{\circ}$ (model WSY 45) was used for the experiment. A manual weld scanner was used in acquisition of the B-scans obtained by scanning the welded bead. These scan results were further analyzed for flaw detection using powerful Image Processing tools in MATLAB.

The gray-scaled images were first pre-processed using techniques such as Contrast-limited Adaptive Histogram Equalization (CLAHE) (which enhances the contrast of the entire image by processing individual tiles of the image), contrast stretching, gray-level slicing and bit-plane slicing. Image enhancement was necessary since the gray-level variations of the image were minute. Noise is also removed in this process. CLAHE was chosen since it operated on smaller portions of the image called tiles instead of the whole image itself. The artificially introduced boundaries are then eliminated using bilinear interpolation technique. CLAHE has the advantage of prevention of over-amplification of the noise signal, when compared to ordinary enhancement techniques.

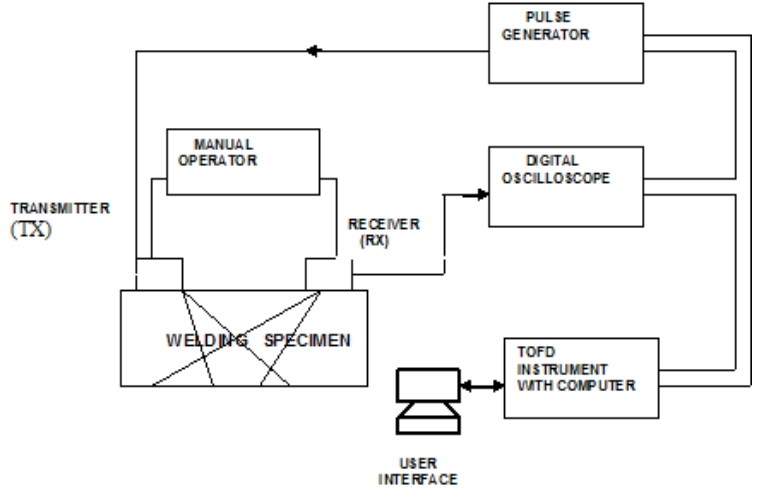

Figure 1: Experimental setup for getting TOFD welding defect signals

\section{SEGMENTATION AND ISOLATION}

An understanding of the B-scan image is now necessary to proceed. The scan result presents in the form of multiple waves ${ }^{[5]}{ }^{[6]}$. The top wave is the lateral wave which is reflected from the top of the specimen and represents the same. The bottom-most wave is the back-wall echo which is reflected from the bottom of the specimen. The distance between these two is the length of the specimen (L). Any defect would present itself as either an abnormal wave or aberrations in between these two waves. If it presents as a set of waves, the top and bottom wave signify the top and bottom of the crack respectively. The distance between these two waves is the defect length. In our case, the flaws mostly presented in the form of aberrations between the lateral wave and back-wall echo due to the smaller size of the defects in question.

Using a MATLAB algorithm, the defect region was manually identified and selected ${ }^{[7]}$. This region is hereby referred to as the Region of Interest (ROI). The ROI was then isolated from the image and further processing was done.

i. The changes in contrast of the given ROI were detected by calculating the gradient. Then, by applying a threshold to this gradient image, a binary mask was created for the segmented image. This binary mask shows just the outlines of the features in the segmented cell.

ii. The binary gradient image is made of lines of high contrast. These lines were minimized by using a dilation technique to obtain dilated gradient image. The gaps which remain in the interior of the ROI can also be filled.

iii. The segmented image was smoothened and presented and any unwanted objects near the ROI were eliminated.

iv. Another option is to show the outline of the detected flaw on the original image itself.

v. The center and the diameter of the flaw were also determined 


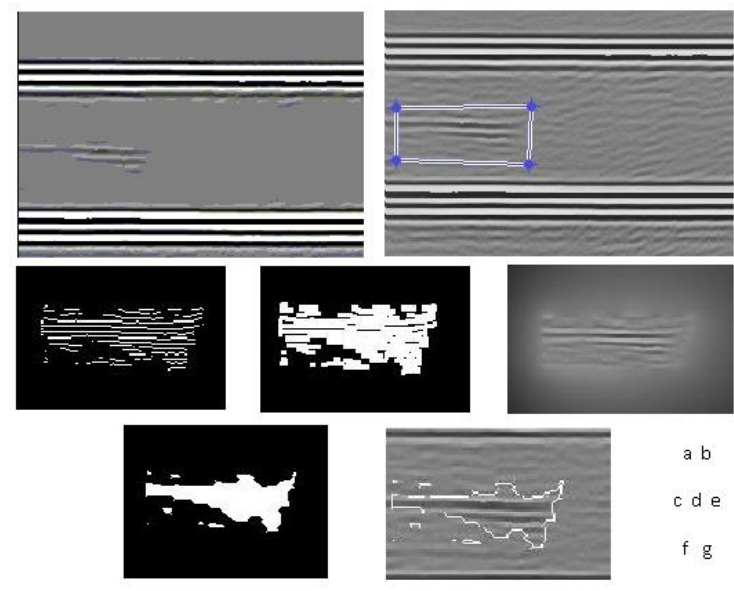

Figure 2: (a) Original Image (b) Enhanced Image (c) Processed with Binary Gradient Mask (d) Processed with Dilated Gradient Mask (e) Isolated image (f) Segmented image (g) Outline of ROI

\section{RESULTS AND DISCUSSION}

The results of a B-scan process have been shown above. We can see that the enhanced image (b) shows the defect more clearly than the original image (a). This is due to increasing the contrast and removing unwanted image noise. The ROI is manually selected as shown highlighted in (a) and the selected portion is isolated by darkening the rest of the image. The isolated image is shown (without any processing) in (e). We can see that when a binary gradient mask is applied to this segmented image (c), the features of the flawed aberration are more defined due to the higher contrast. The false boundaries can be reduced using a dilated gradient mask (d). Figure (f) shows the segmented image, without any feature. This can be considered as the flawed region as a whole. The outline of the flaw alone can be seen highlighted in $(\mathrm{g})$. The center of the flawed area was found to be at $(329,111)$ and diameter was found to be 40 units.

From the image, it can be observed that the binary graded image provides most information required about the type of the flaw, while the segmented outline gives us the general dimension and location of the flaw.

The same processing was done for some more readings and the results are presented below.

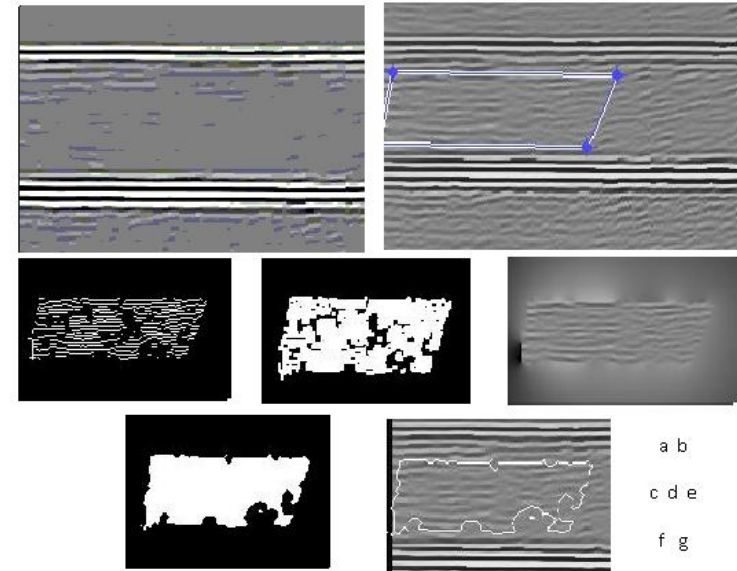

Figure 3: (a) Original Image (b) Enhanced Image (c) Processed with Binary Gradient Mask (d) Processed with Dilated Gradient Mask (e) Isolated image (f) Segmented image (g) Outline of ROI

Center of defect: $(226,138)$

Diameter: 49 units

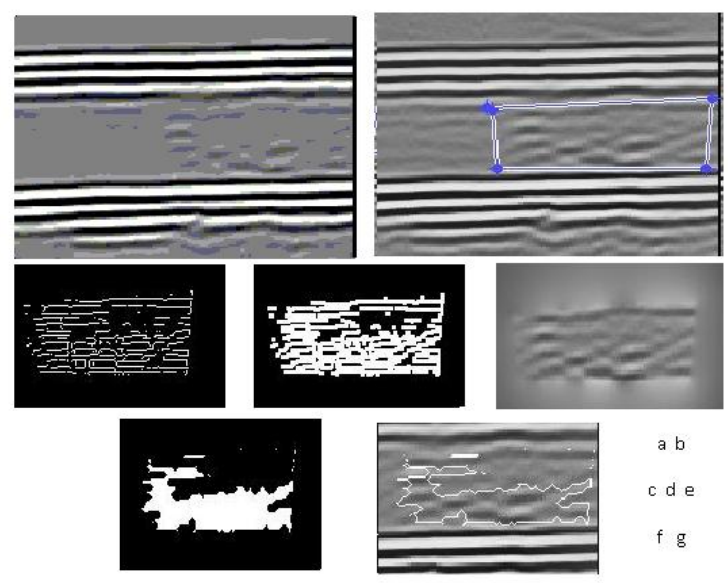

Figure 4: (a) Original Image (b) Enhanced Image (c) Processed with Binary Gradient Mask (d) Processed with Dilated Gradient Mask (e) Isolated image (f) Segmented image (g) Outline of ROI

Center of defect: $(283,430)$

Diameter: 52 units 


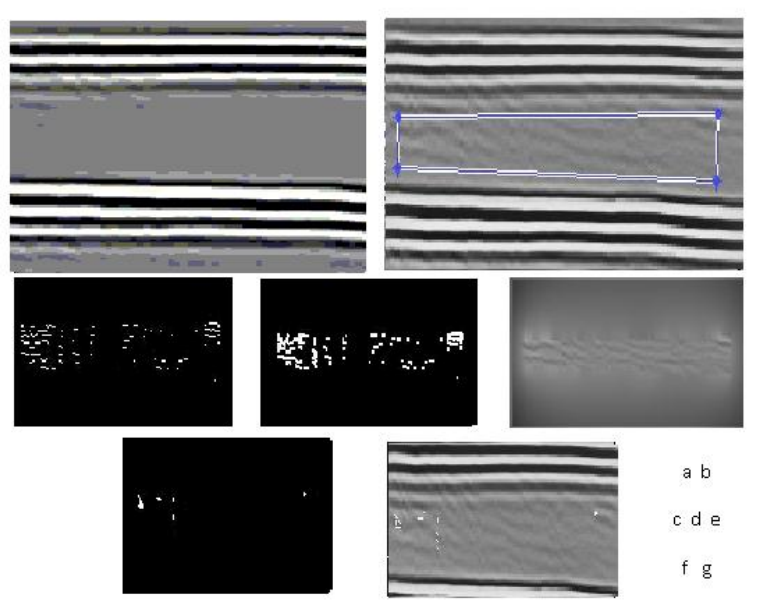

Figure 5. (a) Original Image (b) Enhanced Image (c) Processed with Binary Gradient Mask (d) Processed with Dilated Gradient Mask (e) Isolated image (f) Segmented image (g) Outline of ROI

Fig. 5 shows the analysis of a case without any defects (nearly). This can be observed from the segmented image (f) and from the outlined image $(\mathrm{g})$. The aberrations present in the binary gradient and the dilated gradient processed images can be attributed to noise, which is successfully eliminated by the segmentation. Hence, it is interesting to note that segmentation of the image gives the most accurate detection of the flaw.

\section{INFERENCES AND CONCLUSIONS}

From the results, it can be inferred that the technique is highly accurate when it comes to the detection and location of the flaws. However, the technique is not applicable for multiple flaws individually (since the results give only one centre of defect and diameter) - i.e., the cluster of multiple defects will be treated as one big defect and the results will be obtained for that. Yet, the efficiency and ease of locating the defects is very high in this method. Hence it is very ideal to locate singular defects in the sample under test.

Thus, an innovative technique for the detection and sizing of flaws in welding joints using TOFD technique and Image Processing has been presented. It has been found that image segmentation of the TOFD images leads to easier flaw detection compared to conventional ultrasound technique. The flaw location is also accurately obtained using the same algorithm which highlights the simplicity of processing using MATLAB. Thus, this combinational process can certainly replace conventional UT for flaw detection in welding.

TOFD has the drawback that the weld must be accessible from both the ends to obtain proper scans. This drawback can be overcome by Non-Contact Ultrasound (NCU) [8], which uses ambient air as the acoustic coupling medium.

\section{FUTURE WORK}

The technique described in this paper has been found to be effective for single flaws. More research can be done on the effectiveness of the same in case of multiple flaws present in the signal. The efficiency of the same image processing technique can also be tested on results obtained from Radiographic interpretation ${ }^{[9]}$ of the weld defects. Neural
Network classifiers ${ }^{[10]}$ can also be used to further increase the ease and accuracy of classification.

\section{ACKNOWLEDGMENTS}

Our sincere thanks to IGCAR, Kalpakkam for providing us with the data, without which this paper would not have been possible. We would also like to thank SASTRA University for the invaluable support provided to us in publishing this paper.

\section{REFERENCES}

[1] Wu Xiaomeng, "Detection of Weld Line Defect for Oilgas Pipeline Based on X-rays Image Processing", Proceedings of the 2009 International Symposium on Web Information Systems and Applications (WISA'09), Nanchang, P. R. China, May 22-24, 2009, pp. 273-275

[2] Muthumari S., Vijayarekha K and Amrit Chatterjee, "Comparative Investigation of Split Spectrum Processing over Classical Approach of Filtering for Non-Linear \& Non-Stationary Signals", International Journal of Computer Applications (0975 - 8887), Volume 10No.3, November 2010

[3] General Electricals "Guide to Nondestructive Testing", Advanced Materials \& Processes, June 2008

[4] comprehensive source of information and materials for NDT and NDE technical education available at http://www.ndted.org/GeneralResources/MethodSummar y/MethodSummary.htm

[5] Baskaran G, Krishnan Balasubramaniam and Krishnamurthy C.V., "Inspection Using Shear Wave Time of Flight Diffraction (S-TOFD) Technique", AIP Conference Proceedings, Volume 820, pp. 97-102

[6] I. C. da Silva, M. H. S. Siqueira, D.P.M. Oliveira, R. R. da Silva, A. A. de Carvalho, J. M. A. Rebello, “Automatic

Inspection using the TOFD Technique and Neural Networks", CNDT Barcelona, Vol 8, 2002

[7] Shaun Lawson, "Ultrasonic Testing and Image Processing for In-progress Weld Inspection", NDTnet - April 1996, Vol.1 No.04

[8] Stefano Coccia, Robert Phillips, Claudio Nucera, Ivan Bartoli, Salvatore Salamone, Francesco Lanza di Scalea, Mahmood Fateh, Gary Carr, "Non-Contact Utrasonic Guided-Wave Defect Detection System For Rails", AREMA 2011, September 18-21, 2011, Minneapolis, MN

[9] Erhard A, Ewert U, "The TOFD Method - Between Radiography and Ultrasonic in Weld Testing”, NDT.net September 1999, Vol. 4 No. 9

[10] Lalithakumari S, Sheelarani B, Venkataraman B, Artificial Neural Network Based Classification Of Austenitic Stainless Steel Weld Defects In TOFD Technique", Indian Journal of Computer Science and Engineering (IJCSE), Vol. 2 No. 6 Dec 2011-Jan 2012. 